\title{
Fingerprint Singular Point Detection Based on Modified Poincare Index Method
}

\author{
Gabriel Babatunde Iwasokun ${ }^{1,2}$ and Oluwole Charles Akinyokun ${ }^{3}$ \\ ${ }^{1}$ Department of Web and Multi-Media Computing, Tshwane University of \\ Technology, Pretoria, South Africa \\ ${ }^{2}$ Department of Computer Science, Federal University of Technology, Akure, Nigeria \\ ${ }^{3}$ Department of Physical Sciences, Landmark University, Omu-Aran, Nigeria \\ Imaxtunde@yahoo.com, ${ }^{3}$ akinwole2003@yahoo.co.uk
}

\begin{abstract}
The use of fingerprint for human identity management has been on the rise lately. Reasons adduced for this include its high level of uniqueness, availability, consistency and universality. The task of human identity management based on fingerprint technology involves a number of processes which include enrolment, enhancement, feature and singular points detection and extraction and pattern matching. Detection and extraction of genuine and reliable feature and singular points are paramount for reliable pattern matching. The limitations of some existing fingerprint singular point detection algorithms include inaccurate detection and failure with some fingerprint pattern and poor quality images. In this paper, a modified Poincare Index fingerprint singular point detection algorithm is proposed for resolving these limitations. The results of the experimental study of the new algorithm on Dataset DB1 of FVC2000 standard fingerprint database show that the new algorithm reliably and adequately detected singular points from fingerprints of all patterns and qualities.
\end{abstract}

Keywords: Fingerprint, singular point detection, Poincare index, orientation estimation

\section{Introduction}

Fingerprint matching is majorly performed in fingerprint-based human verification and identification systems. It is also performed when the need for establishing the degree of resemblance among different fingerprints arises. Fingerprint matching involves the use of coarse and smooth level characteristics of fingerprint. At the coarse level, fingerprints are classified into six main classes; namely arch, tented arch, right loop, left loop, whorl and twin loop which are shown in Figure 1 [1-7].

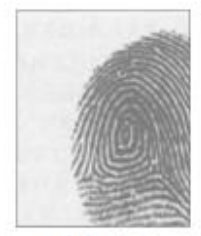

Twin Loop

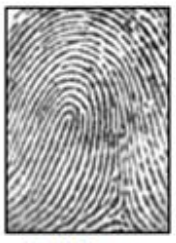

Left Loop

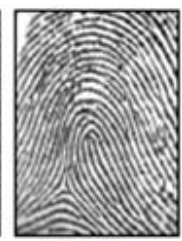

Right Loop

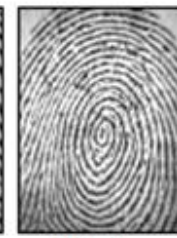

Whorl

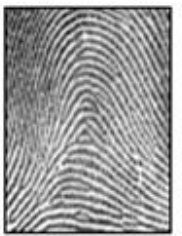

Arc

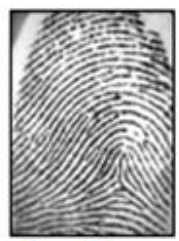

Tented Arc

Figure 1. Fingerprint Ridge Patterns

Smooth-level fingerprint matching involves a comparison among the feature (ridge ending, bifurcation and the singular points) sets extracted from fingerprint images. As shown in 
Figure 2(a), the ridge terminates at the ridge ending while it splits into two at a bifurcation point. The singular point is the point where the ridge orientation field experiences discontinuity either through the ridge curvature rising higher than normal or the ridge changes rapidly resulting in a zero gradient. Singular points can be classified into two types; namely core and delta which are shown in Figure 2(b) [8].

At the core point, the pattern exhibits a semi-circular tendency whereas the patterns split into three different sectors at the delta point, and each sector exhibits the hyperbolic tendency [9-10]. Singular points are used for fingerprint indexing, classification, arrangement and orientation field modelling [10-13]. They are also parts of the core components of several fingerprint matching algorithms $[11,14]$.

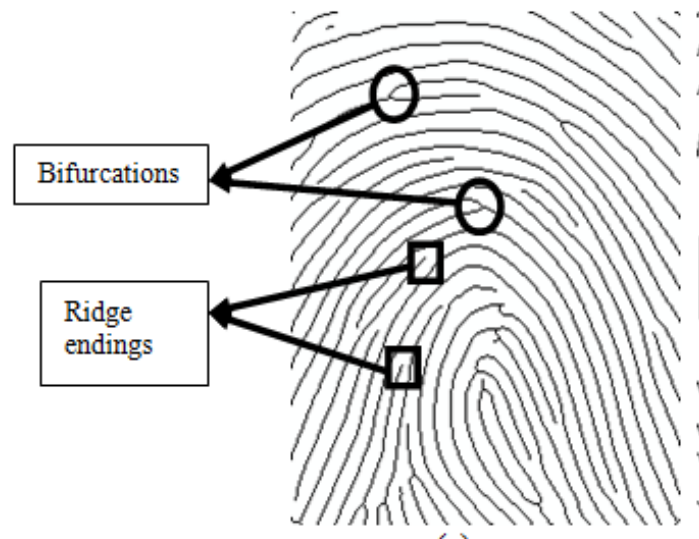

(a)

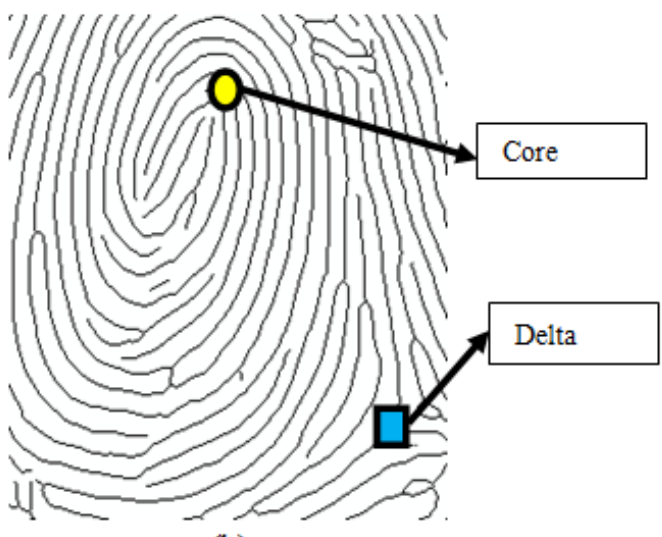

(b)

Figure 2. (a) Fingerprint Showing the Bifurcation and Ridge ending (b) Fingerprint Showing the Core and Delta Points

The existing fingerprint singular point detection algorithms include Poincare Index [9, 1517], Curvature [18], Multi-Resolution [14] and Orientation Field [19-22]. In several cases, the existing techniques for the detection of the singular points do not produce expected or accurate results, especially for noisy images [23-24]. Some of the algorithms are selective in the nature of their performances, others failed with some patterns of fingerprint $[1,25]$ and some result in many forged detection points. Forged detections are due to inaccurate algorithms and use of only local characteristic of singular points by most post-processing approaches, which is not enough to discriminate true singular points from forged detections caused by creases, scars, blurs, damped prints and so on $[8,26]$.

Singular points detection methods may also suffer from cropping of the Region of Interest (ROI) thereby containing less information [27]. With a view to addressing the highlighted problems of existing fingerprint singular point detection methods, a modified Poincare index fingerprint singular point detection method is proposed in this research. Synopses of related works on fingerprint singular point detection formed the focus of Section 2 while Section 3 presents the modified Poincare index fingerprint singular point detection method. Sections 4 and 5 present the experimental study of the new algorithm and the conclusion drawn respectively.

\section{Précis of Related Works}

The précis of some existing works on fingerprint singular point detection is presented in Table 1 . The authors in $[1,10,28-31,32]$ presented different techniques based on orientation 
field estimation for reliable detection of fingerprint singular point. The authors in [33] employed orientation field, localization and type for fingerprint singular points detection while an algorithm which is based on orientation field estimation, coherence and Poincare Index (PI) methods is used for core point detection in [8, 34-35]. The algorithms detect high curvature regions with high accuracy by combining the strengths of the individual methods. Some of the algorithms used optimal combination of singular points to minimize the difference between the original and the model-based orientation field. Core-delta relation is also used as global constraint for the final selection of singular points. The authors in [24] presented an algorithm that uses Multi-Resolution Direction Field (MRDF) and HighResolution Direction Field (HRDF) to search and locate the positions of fingerprint singular points.

A technique that estimates the positions of the singular points in fingerprint image by processing the global structure of the ridges and extracting a specific set of features is presented in [36]. Computational intelligence classification techniques were used to process the extracted features for the selection of the singular point from the candidate list. The authors in [37] presented a model for determining virtual core point based on changes in gradient at the maxima and minima points while a similar method based on Gaussian processes for the prediction of the locations and orientations of core points for latent fingerprints is proposed in [38]. The method also provides prediction in interpretations of probability rather than binary decision. Direction of Curvature (DC) is used in [26] for the determination of fingerprint core point while Geometry of Region (GR) is used in its tuning. The reference point of a fingerprint is located in [39] based on the rotation-invariant location and Filter-bank-based algorithm. The authors in [40] used a directional masks to detect the neighbourhood of the singular points while Principal Gabor Basis Function (PGBF)-based approach is used in [41] to extract cores, deltas and minutiae from fingerprint images.

Table 1. Summary of Some Existing Works on Fingerprint Singular Point Detection

\begin{tabular}{|l|l|l|l|}
\hline Research & Methodology & Strength & Weakness \\
\hline Bo et al. [1] & Poincare Index & $\begin{array}{l}\text { Extraction of } \\
\text { singular points with } \\
\text { high accuracy }\end{array}$ & $\begin{array}{l}\text { Susceptible to forged } \\
\text { detection }\end{array}$ \\
\hline $\begin{array}{l}\text { Kharat and } \\
\text { Kodwe [8] }\end{array}$ & $\begin{array}{l}\text { Poincare Index and } \\
\text { DORIVAC }\end{array}$ & $\begin{array}{l}\text { Removal of forged } \\
\text { detections }\end{array}$ & $\begin{array}{l}\text { Computationally } \\
\text { expensive }\end{array}$ \\
\hline $\begin{array}{l}\text { Anwar et al. } \\
\text { [10] }\end{array}$ & Poincare Index & $\begin{array}{l}\text { Detect all the cores } \\
\text { and deltas in an } \\
\text { image }\end{array}$ & $\begin{array}{l}\text { The operational } \\
\text { speed is low due to } \\
\text { un-optimized } \\
\text { procedures. }\end{array}$ \\
\hline $\begin{array}{l}\text { Bazen and } \\
\text { Gerez [16] }\end{array}$ & Directional Field & $\begin{array}{l}\text { Accurate detection of } \\
\text { singular point and } \\
\text { orientation }\end{array}$ & $\begin{array}{l}\text { Diminishing } \\
\text { performance with } \\
\text { low quality images }\end{array}$ \\
\hline $\begin{array}{l}\text { Zhang and } \\
\text { Wang [24] }\end{array}$ & $\begin{array}{l}\text { Multi-Resolution } \\
\text { Directional Field }\end{array}$ & $\begin{array}{l}\text { Higher precision and } \\
\text { robust to noise }\end{array}$ & $\begin{array}{l}\text { Computationally } \\
\text { expensive }\end{array}$ \\
\hline $\begin{array}{l}\text { Julasayvake } \\
\text { and } \\
\text { Choomchuay } \\
\text { [26] }\end{array}$ & Region of Interest & $\begin{array}{l}\text { Accurate core point } \\
\text { detection with less } \\
\text { computation load }\end{array}$ & $\begin{array}{l}\text { Susceptible to false } \\
\text { detection }\end{array}$ \\
\hline $\begin{array}{l}\text { Song and } \\
\text { Elliot [29] }\end{array}$ & $\begin{array}{l}\text { Orientation and } \\
\text { Edge-Map }\end{array}$ & $\begin{array}{l}\text { Singular points } \\
\text { detection with high }\end{array}$ & $\begin{array}{l}\text { Medium } \\
\text { performance in case }\end{array}$ \\
\hline
\end{tabular}




\begin{tabular}{|l|l|l|l|}
\hline & speed and accuracy & $\begin{array}{l}\text { of arch fingerprint } \\
\text { type }\end{array}$ \\
\hline $\begin{array}{l}\text { Khalil et al. } \\
{[30]}\end{array}$ & $\begin{array}{l}\text { Orientation } \\
\text { field/Short Time } \\
\text { Fourier Transform } \\
\text { Analysis }\end{array}$ & $\begin{array}{l}\text { Consistent and } \\
\text { accurate extraction of } \\
\text { singular points }\end{array}$ & $\begin{array}{l}\text { Failed with poor } \\
\text { quality image }\end{array}$ \\
\hline $\begin{array}{l}\text { Fei et al. } \\
\text { [32] }\end{array}$ & $\begin{array}{l}\text { Orientation Field and } \\
\text { Zero Pole models }\end{array}$ & $\begin{array}{l}\text { Consistently extract } \\
\text { singular points with } \\
\text { high accuracy and } \\
\text { speed }\end{array}$ & $\begin{array}{l}\text { Fails in fingerprint } \\
\text { with inconsistent } \\
\text { orientation field }\end{array}$ \\
\hline $\begin{array}{l}\text { Mei et al. } \\
\text { [33] }\end{array}$ & $\begin{array}{l}\text { Orientation Field } \\
\text { Partitioning }\end{array}$ & $\begin{array}{l}\text { Promotion of } \\
\text { accurate extraction of } \\
\text { singular points }\end{array}$ & $\begin{array}{l}\text { Uncertainty in cases } \\
\text { of poor quality } \\
\text { images }\end{array}$ \\
\hline $\begin{array}{l}\text { Kekre and } \\
\text { Bharadi [34] }\end{array}$ & $\begin{array}{l}\text { Orientation Field } \\
\text { Based on Multiple } \\
\text { Features }\end{array}$ & $\begin{array}{l}\text { Core point detection } \\
\text { with very high } \\
\text { accuracy }\end{array}$ & $\begin{array}{l}\text { Only detect core } \\
\text { points for loop } \\
\text { images }\end{array}$ \\
\hline $\begin{array}{l}\text { Weng et al. } \\
\text { [35] }\end{array}$ & $\begin{array}{l}\text { Multi-Resolution and } \\
\text { Poincare Index }\end{array}$ & $\begin{array}{l}\text { Erasure of noise } \\
\text { induced singular } \\
\text { points }\end{array}$ & $\begin{array}{l}\text { Fail when image has } \\
\text { resolution problem }\end{array}$ \\
\hline $\begin{array}{l}\text { Basak et al. } \\
\text { [37] }\end{array}$ & Gradient Changes & $\begin{array}{l}\text { Detect virtual core } \\
\text { points }\end{array}$ & $\begin{array}{l}\text { Result not suitable } \\
\text { for fingerprint } \\
\text { classification }\end{array}$ \\
\hline $\begin{array}{l}\text { Chang and } \\
\text { Sargur [38] }\end{array}$ & Gaussian Process & $\begin{array}{l}\text { Core point detection } \\
\text { for images with or } \\
\text { without virtual core } \\
\text { points }\end{array}$ & $\begin{array}{l}\text { Only based on } \\
\text { probability measure }\end{array}$ \\
\hline $\begin{array}{l}\text { Sim et al. } \\
\text { [39] }\end{array}$ & $\begin{array}{l}\text { Rotation Invariant } \\
\text { Reference Point } \\
\text { Location }\end{array}$ & $\begin{array}{l}\text { Dependent on } \\
\text { sectors and filter } \\
\text { sizes }\end{array}$ \\
\hline
\end{tabular}

\section{Modified Poincare Index Technique}

The traditional Poincare Index technique, though susceptible to forged detection, is one of the commonly used techniques for fingerprint core and delta point detections $[1,10]$. In a fingerprint orientation field, the PI of a core-shaped singular region is 0.5 while that of a delta-shaped singular region is -0.5 . For pixel $\mathrm{P}(\mathrm{i}, \mathrm{j})$, its PI is obtained from $[1,8,10,35,42]$ :

$$
\begin{aligned}
& P C(i, j)=\frac{1}{2 \pi} \sum_{k=0}^{N_{P}-1} \Delta(k) \\
& \Delta(k)=\left\{\begin{array}{lc}
\delta(k), & \text { if } \delta(k)<\frac{\pi}{2} \\
\pi+\delta(k), & \text { if } \delta(k) \leq-\frac{\pi}{2} \\
\pi-\delta(k), & \text { otherwise }
\end{array}\right. \\
& \delta(k)=O^{\prime}\left(P_{x}\left(k^{\prime}\right), P_{y}\left(k^{\prime}\right)\right)-O^{\prime}\left(P_{x}(k), P_{y}(k)\right), \\
& k^{\prime}=(k+1) \bmod N_{P}
\end{aligned}
$$

$P_{x}(k)$ and $P_{y}(k)$ are the $\mathrm{x}$ and y coordinates of the kth point on the closed curve centered at the given point $(\mathrm{i}, \mathrm{j})$ and composed of $\mathrm{N}_{\mathrm{P}}$ pixels, $O^{\prime}$ denotes a fingerprint orientation field. To 
capture the sudden change of orientation, and extract singular points more reliably, the method is improved by modulating the third part of Equation (2) to $\delta(k)-\pi$ which results in [35]

$$
\Delta(k)=\left\{\begin{array}{lr}
\delta(k), & \text { if } \delta(k)<\frac{\pi}{2} \\
\pi+\delta(k), & \text { if } \delta(k) \leq-\frac{\pi}{2} \\
\delta(k)-\pi, & \text { otherwise }
\end{array}\right.
$$

Post-processing steps are often used to resolve associated anomalies in the following ways:

a. Both delta and core are eradicated if the distance between them is smaller than 8 pixels

b. In a circular region with a radius of 8 pixels, if there is more than one core (or delta), an average core (or delta) is calculated instead. Given that $N$ cores (or deltas) exist in an area, $\left\{\left(\mathrm{u}_{\mathrm{i}}, \mathrm{v}_{\mathrm{i}}\right), \mathrm{i}=1,2,3, \ldots, \mathrm{N}\right)$ then, the average core (or delta) $(u, v)$ is calculated from:

$$
\begin{gathered}
u=\frac{1}{N} \sum_{i=1}^{N} u_{i} \\
V=\frac{1}{N} \sum_{i=1}^{N} v_{i}
\end{gathered}
$$

The modified Poincare index singular point detection method is in two major steps, namely ridge orientation estimation and singular point detection.

\subsection{The Ridge Orientation Estimation}

The ridge orientation estimation is in the following phases:

3.1.1. Image Segmentation: A fingerprint image contains the foreground and the background regions. The foreground is the region of interest (ROI) and contains the ridges and valleys while the background is the outside region containing noise and contaminants. The foreground is the region of high variance while the background is the region of low variance [43]. Based on these characteristics, a method which is based on variance levels is used to segment the foreground from the background. The method divides the image into blocks of size $\mathrm{W} \times \mathrm{W}$ and the variance, $\mathrm{V}(\mathrm{k})$ for all the pixels in block $\mathrm{k}$ is then calculated from:

$$
V(k)=\frac{1}{W^{2}} \sum_{i=1}^{W} \sum_{j=1}^{W}(I(i, j)-M(k))^{2}
$$

$I(i, j)$ represents the grey-level value for pixel $i, j$ in block $k$ and $M(k)$ is the average grey-level value for block $\mathrm{k}$.

3.1.2. Image Ridge Normalization: Ridge normalization is used to adjust and standardize the fingerprint grey-level values to a range that is suitable for best image contrast and brightness. During normalization, the segmented image is firstly divided into blocks of size $S$ $\mathrm{x} \mathrm{S}$ and then for each block, a comparison is made between each pixel's grey-level and the average grey-level values. Given that $\mathrm{M}_{0}$ and $\mathrm{V}_{0}$ are the desired mean and variance respectively, the normalized grey-level value $N(i, j)$ for pixel $I(i, j)$ belonging to a block of average grey-level value $\mathrm{M}$ and variance $\mathrm{V}$ is obtained from: 


$$
N(i, j)= \begin{cases}M_{0}+\sqrt{\frac{V_{0}(I(i, j)-M)^{2}}{V}} & \text { if } I(i, j)>M \\ M_{0}-\sqrt{\frac{V_{0}(I(i, j)-M)^{2}}{V}} & \text { otherwise }\end{cases}
$$

3.1.3. Orientation Estimation: The orientation at a particular pixel is the direction of the flow of the ridges over it and it is derived based on the following steps [14]:

a. Firstly, blocks of size $S x S$ are formed in the normalized image.

b. For each pixel $(\mathrm{p}, \mathrm{q})$ in each block, the gradients $\partial_{x}(p, q)$ and $\partial_{y}(\mathrm{p}, \mathrm{q})$, which represent the gradient magnitudes in the $x$ and $y$ directions, respectively are computed. $\partial_{x}(\mathrm{p}, \mathrm{q})$ and $\partial_{y}(\mathrm{p}, \mathrm{q})$ are computed using any of the gradient operators.

c. $V_{x}, V_{y}$ and the least mean square, $\theta$ of the local orientation for each block centered at pixel I(i,j) are then computed from:

$$
\begin{aligned}
& V_{x}(i, j)=\sum_{p=i-\frac{S}{2}}^{i+\frac{S}{2}} \sum_{q=j-\frac{S}{2}}^{j+\frac{S}{2}} 2 \partial_{x}(p, q) \partial_{y}(p, q) \\
& V_{y}(i, j)=\sum_{p=i-\frac{S}{2}} \sum_{q=j-\frac{S}{2}}^{j+\frac{S}{2}} \partial_{x}^{2}(p,)-\partial_{y}^{2}(p, q) \\
& \theta(i, j)=\frac{1}{2} \tan ^{-1} \frac{V_{y}(i, j)}{V_{x}(i, j)}
\end{aligned}
$$

d. $\varphi_{x}$ and $\varphi_{y}$, which are the $x$ and $y$ components of the vector field of $\theta$, are computed as follows:

$$
\begin{gathered}
\varphi_{x}(i, j)=\cos (2 \theta(i, j)), \\
\varphi_{y}(i, j)=\sin (2 \theta(i, j)),
\end{gathered}
$$

e. The vector field is then smoothened as follows:

$$
\begin{gathered}
\varphi_{X}^{\prime}(i, j)=\sum_{p=-\frac{s_{\varphi}}{2}}^{\frac{s_{\varphi}}{2}} \sum_{q=-\frac{s_{\varphi}}{2}}^{\frac{s_{\varphi}}{2}} G(p, q) \varphi_{x}(i-p s, j-q s) \\
\varphi_{y}^{\prime}(i, j)=\sum_{p=-\frac{s_{\varphi}}{2}}^{\frac{s_{\varphi}}{2}} \sum_{q=-\frac{s_{\varphi}}{2}}^{\frac{s_{\varphi}}{2}} G(p, q) \varphi_{y}(i-p s, j-q s)
\end{gathered}
$$

$G$ is a Gaussian low-pass filter of size $S_{\varphi} X S_{\varphi}$.

f. $O(i, j)$, which is the smoothened orientation field of the block centered at pixel $(i, j)$ is obtained from:

$$
O(i, j)=\frac{1}{2} \tan ^{-1} \frac{\varphi_{y}^{\prime}(i, j)}{\varphi_{x}^{\prime}(i, j)}
$$

\subsection{Singular Points Detection}

The detection of the singular point characteristics for a pixel $(i, j)$ is derived based on a modified Poincare Index method presented as follows: 


$$
\begin{aligned}
& P C(i, j)=\frac{1}{\pi} \sum_{c=1}^{8} \beta_{c}, \\
& \beta_{c}=\left\{\begin{array}{cc}
p(c)+\pi, & \text { if } p(c) \leq-\frac{\pi}{2} \\
p(c), & \text { if } p(c)>-\frac{\pi}{2} \text { and } p(c) \leq \frac{\pi}{2} \\
p(c)-\pi, & \text { otherwise }
\end{array}\right. \\
& p(c)=\left|O_{c+1}-O_{c}\right|, \quad O_{9}=O_{1}
\end{aligned}
$$

$\mathrm{O}_{1}, \mathrm{O}_{2}, \ldots, \mathrm{O}_{8}$ represent the orientations of the $3 \times 3$ neighbors of pixel $(\mathrm{i}, \mathrm{j})$ which are scanned in the direction shown in Figure 3.

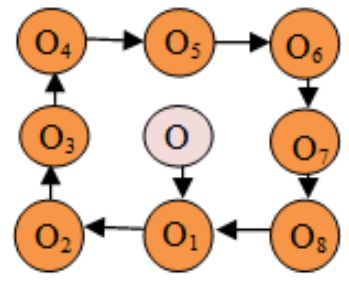

\section{Figure 3. 8 Neighbors of a Candidate Pixel}

Based on these characteristics, the core point lies within the range of -1 and -0.5 for $\mathrm{PC}(\mathrm{i}, \mathrm{j})$ while the delta point is within in the range 0.5 - 1.0. In some fingerprint images, these characteristics produced some false core and delta points which are eliminated by using the post-extraction algorithm as follows:

a. Given that $N$ cores (or deltas) defined by $\left(\mathrm{u}_{\mathrm{i}}, \mathrm{v}_{\mathrm{i}}\right), \mathrm{i}=1,2,3, \ldots, \mathrm{N}$ exist in a circular region of radius of 8 pixels, then the coordinate of the average core (or delta) at point $(u, v)$ is calculated from:

$$
\begin{aligned}
& u=\aleph\left(u_{1}+u_{2}+u_{3} \ldots+u_{N}\right) \\
& v=\kappa\left(v_{1}+v_{2}+v_{3} \ldots+v_{N}\right)
\end{aligned}
$$

$\mathbb{N}$ is the average operation.

b. Both delta and core points are eliminated if they are within 8 pixels distance.

\section{Experimental Study}

The experimental study of the modified Poincare index fingerprint singular point detection algorithm was performed using Matlab in an environment characterized by windows 7 Operating System on an Intel (R) $2.50 \mathrm{GHz}$ dual core Pentium IV with 4.0 GByte RAM. Fingerprint images of diverse qualities from dataset DB1 of FVC2000 fingerprint database were used for the study. Each of the images is of size $300 \times 300$ pixels and captured using optical sensor at resolution of 500 dots per inch (dpi) [44]. The genuineness of the extracted core and delta points based on visual inspections formed the basis for the evaluation. Some of the images in the dataset are presented in Figures 4(a-e) representing right loop (plus arch), right loop, arch, whorl and tented arch patterns respectively. 


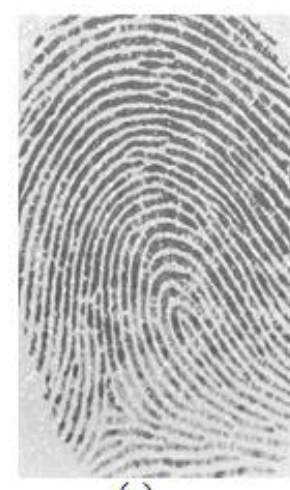

(a)

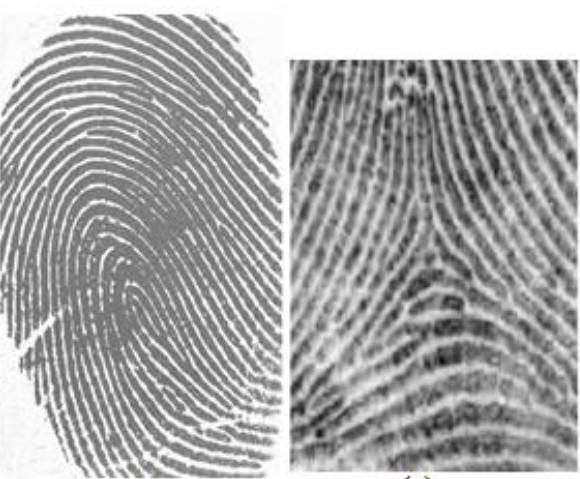

(b) (c)

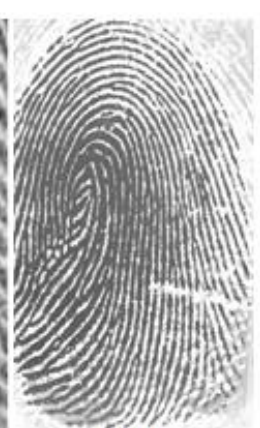

(d)

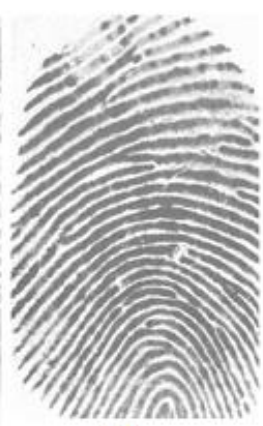

(e)

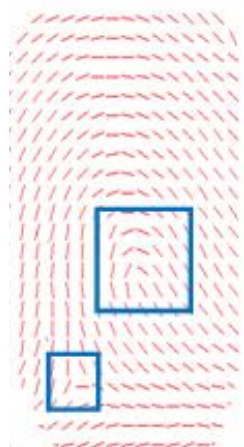

(f)

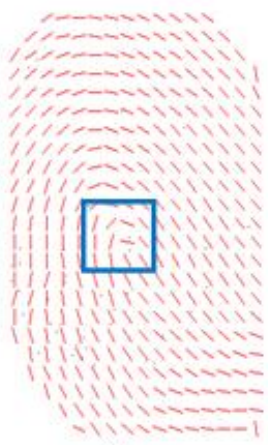

(g)

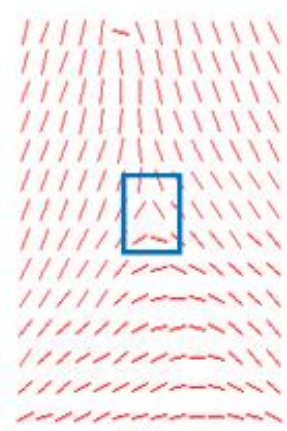

(h)

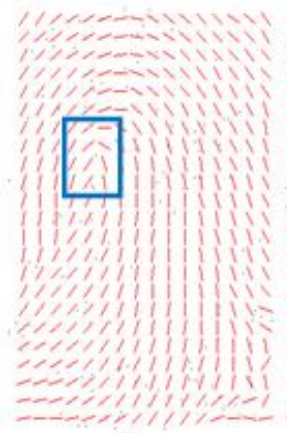

(i)

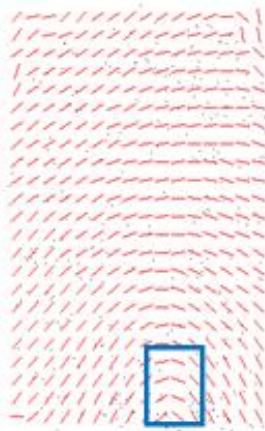

(j)

\section{Figure 4. Fingerprints and their Orientation Estimates}

Since the modified algorithm is functionally dependent on image ridge orientation, the suitability of the ridge orientation estimation algorithm for effective computation of the ridge orientations was investigated. The results of the investigation (parts of which are presented in Figures $4(\mathrm{f}-\mathrm{j})$ show that irrespective of the fingerprint pattern, there is a very accurate and reliable estimation of the ridge orientations. The suitability of the ridge orientation estimation algorithm is therefore established. In the orientation images, the ROI, which have potential for core or delta point, are annotated with squares.

The results of the extraction of multiple core (in red) and delta (in blue) points from these images are shown in Figures 5(a-e). The thick and overlapping nature of the extractions show combination of several (forged) core or delta points within circular region of 8 or more pixels. Visual inspection of the results of the extractions also shows that some false core and delta points were extracted in several images. The results of the implementation of the postextraction algorithm on these images are presented in Figures 6(a-e). The post-extraction results show complete elimination of all forged singular points as well as overlapping. The results of Figure 6 also present how the new algorithm appropriately detected and extracted core or delta point from the ROI of images of different patterns. 


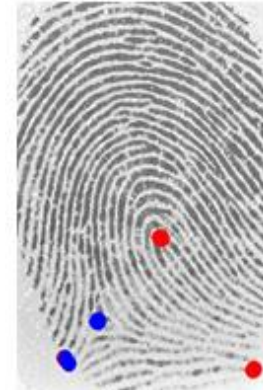

(a)

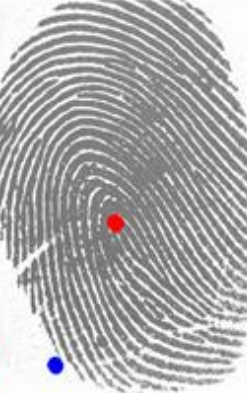

(b)

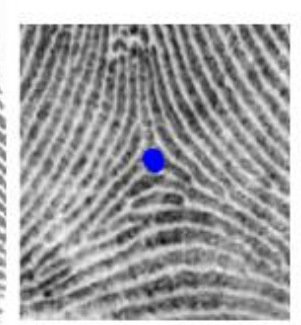

(c)

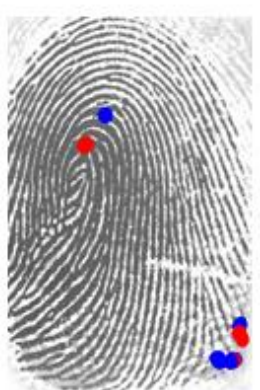

(d)

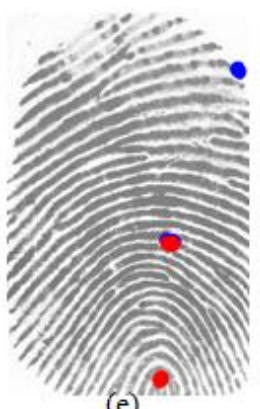

(e)

Figure 5. Multiple Singular Points Extractions

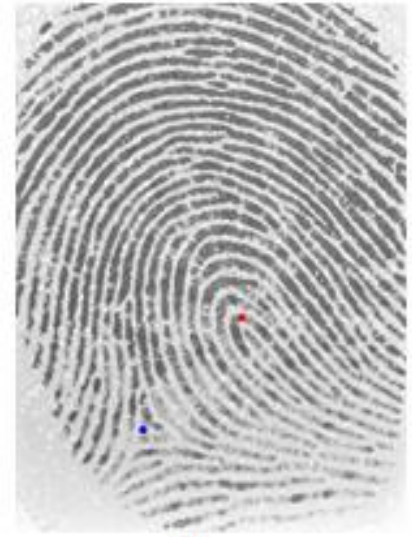

(a)

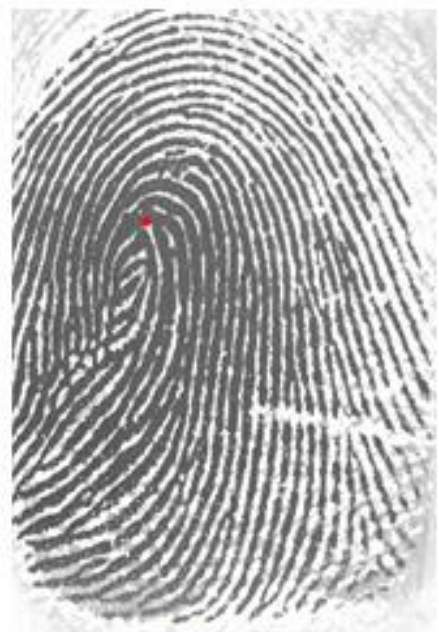

(d)

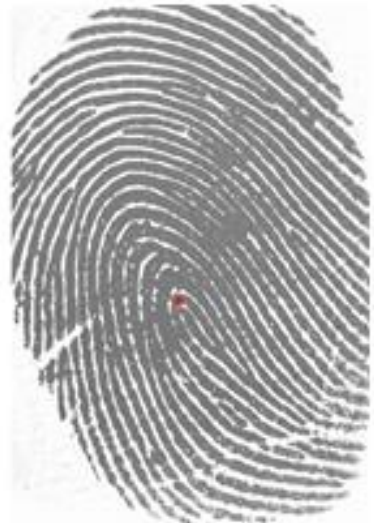

(b)

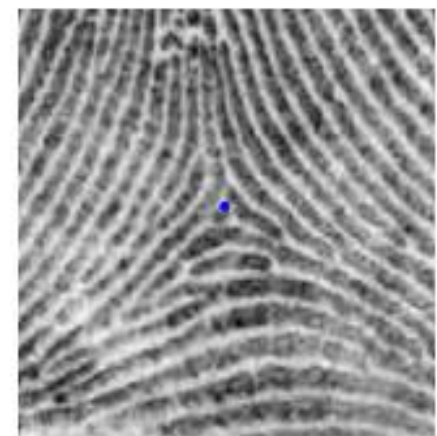

(c)

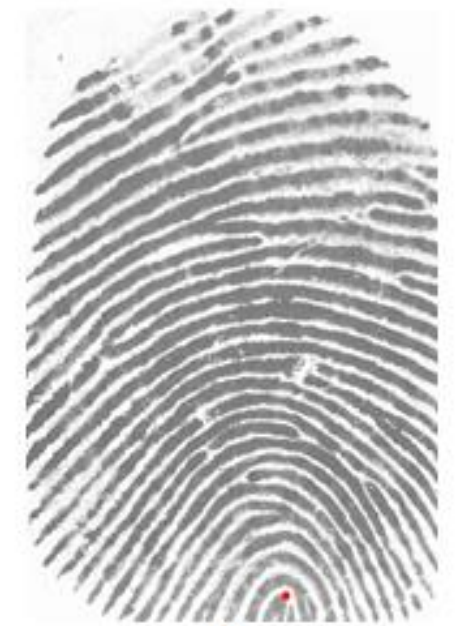

(e)

Figure 7. Presents Accurate Detection of Singular Points for Medium Quality Images

However, the new algorithm failed with very poor quality images as shown in Figure 8(ab). The inaccurate extractions are attributed to the misleading forms of the estimated orientation images as shown in Figures 8(c-d). The results presented in Figures 5-8 show clearly that the performance of the new algorithm is significantly dependent on the quality of 
the image. Accurate and true detection and extraction are attained if the image is of high or medium quality while inaccurate and false detections are recorded for highly degraded images.

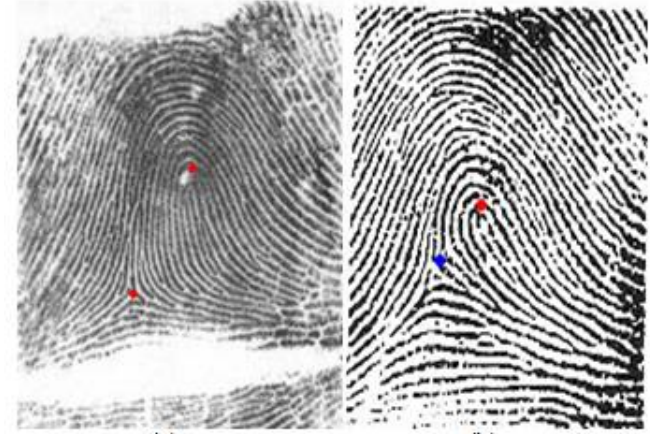

(a)

(b)

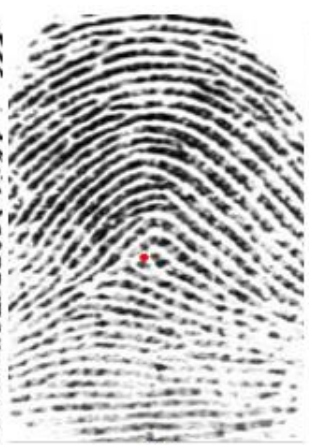

(c)

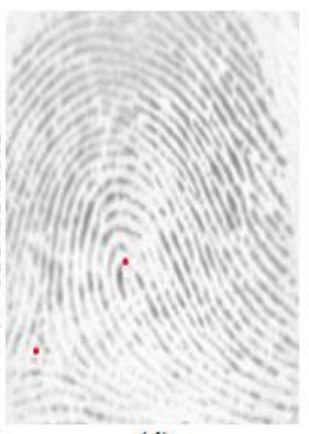

(d)

Figure 7. Singular Point Extraction for Poor Quality Images

Some of the results of the implementation of the original Poincare algorithm are presented in Figure 9. Visual inspection and comparison of the extracted singular point with those in Figure 6 shows more accurate results for the new algorithm.

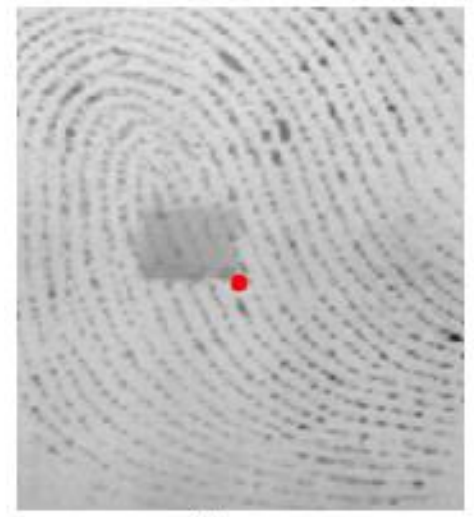

(a)

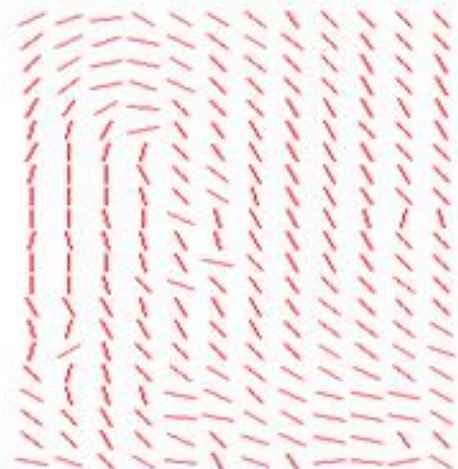

(c)

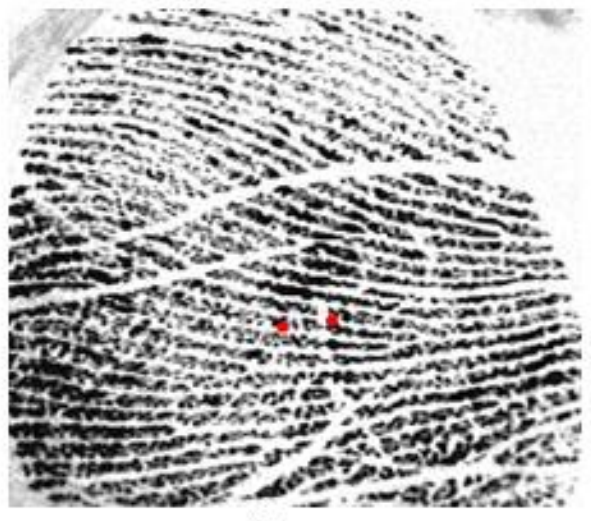

(b)

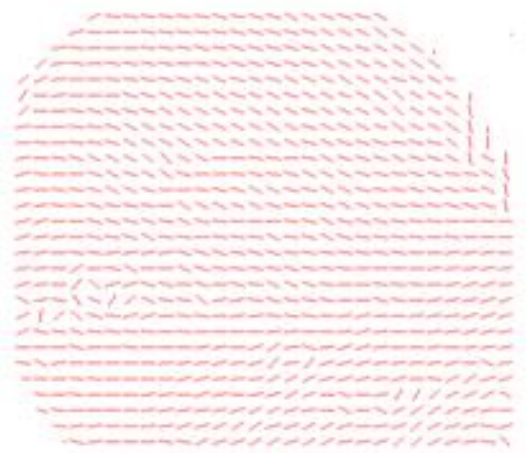

(d)

Figure 8. Singular Point Extraction for Poor Quality Images 


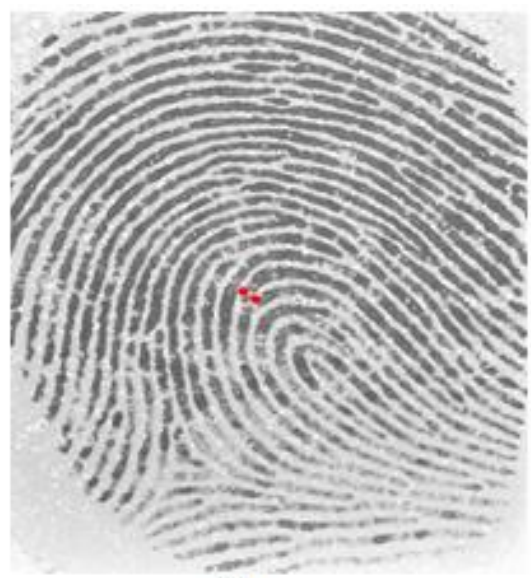

(a)

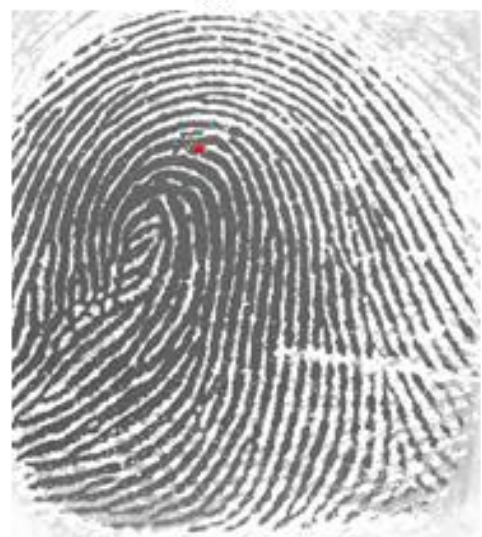

(c)

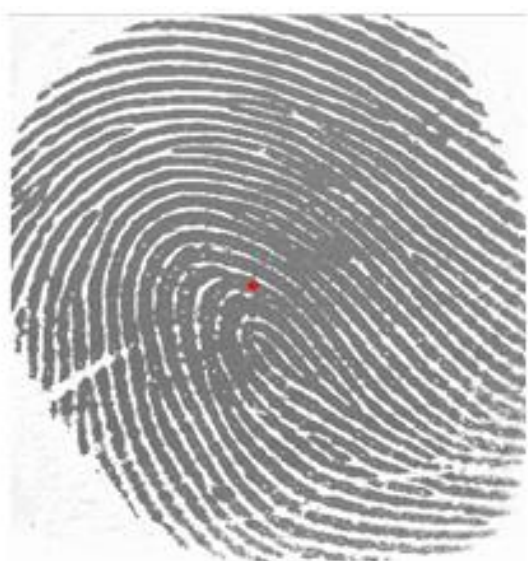

(b)

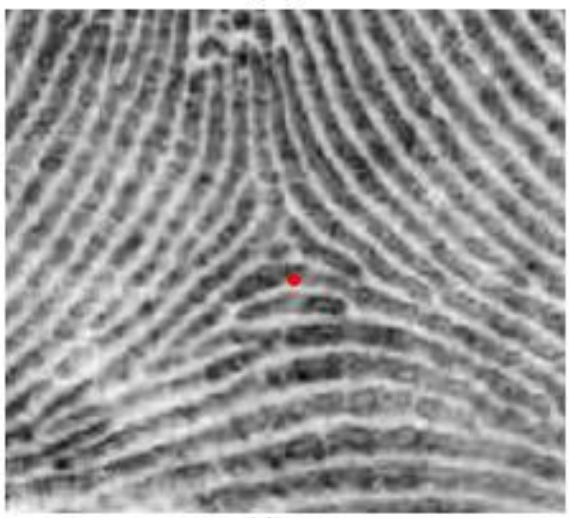

(d)

\section{Figure 9. Results for Original Poincare Algorithm}

\section{Conclusion}

This paper presents the experimental study of a modified Poincare Index method for fingerprint singular point detection. Obtained results from the experimental study indicate that the new algorithm improved on some of the existing ones through adequate and superior detection and extraction of singular points from good quality images of different pattern. The major limitation of the Poincare index method, which is forged detection, had been eliminated by the new algorithm. The new algorithm is also suitable for implementation with image of medium quality in which some common algorithms had suffered poor detections and extractions. Future research focuses at improving on the new technique to boost its performance with poor quality images.

\section{References}

[1] J. Bo, H. P. Tang and M. L. Xu, "Fingerprint Singular Point Detection Algorithm by Poincaré Index", WSEAS Transactions on Systems, vol. 7, no. 12, (2008).

[2] D. Salter, "Thumbprint An Emerging Technology", Engineering Technology, New Mexico State University, (2006), Available: http://technologyinterface.nmsu.edu/summer97/security/ finger.html, Accessed 15/03/214

[3] "FIDIS, Future of Identity in the Information Society", Elsevier Incorporation, (2006), Available: cosic.esat.kuleuven.be/publications/article-929.pdf, Accessed 15/03/2014. 
[4] W. G. Eckert, "Introduction to Forensic Science", New York: Elsevier, (1996), Available: http://www.amazon.co.uk/Introduction-Forensic-Sciences-Edition-Library/dp/0849381010.

[5] J. Wayman, D. Maltoni, A. K. Jain and D. Maio, "Biometric Systems", Springer-Verlag London Limited, (2005).

[6] O. C. Akinyokun and E. O. Adegbeyeni, "Scientific Evaluation of the Process of Scanning and Forensic Analysis of Thumbprints on Ballot Papers", Proceedings of Academy of Legal, Ethical and Regulatory Issues, New Orleans, vol. 13, no. 1, (2009).

[7] L. Yount, "Forensic Science: From Fibres to Thumbprints", Chelsea House Publisher, (2007).

[8] P. K. Vyankatesh, S. K. Sumedh, "Detection of Singular Points from Fingerprint Images Using an Innovative Algorithm", Journal of Computer Engineering and Intelligent Systems, vol. 3, no. 5, (2005).

[9] L. Hong and A. K. Jain, "Classification of Fingerprint Images", Proceedings of Eighth Scandinavian Conference on Image Analysis, Kangerlussuaq, Greenland, (1999), Available: www.cse.msu.edu0 /biometrics /Publications/ Fingerprint/clas.pdf.

[10] R. M. Anwar, M. U. Akram, R. Arshad and M. U. Munir, "A Modified Singular Point Detection Algorithm", ICIAR 2008, LNCS 5112, (2008), pp. 905-914.

[11] D. Maltoni, D. Maio, A. K. Jain and S. Prabhakar, "Handbook of Fingerprint Recognition", Springer, Heidelberg, (2003).

[12] A. Jain and B. S. P. Ruud, "Biometrics Personal Identification. Networked Society of Kluwer Academic Publishers, Dordrecht, (1998).

[13] D. Maio and D. Maltoni, "Direct Gray-Scale Minutiae Detection in Fingerprints", IEEE Transactions on Pattern Analysis and Machine Intelligence, vol. 19, (1997), pp. 27-40.

[14] A. K. Jain, S. Prabhakar L. Hong and S. Pankanti, "Filter bank-Based Fingerprint Matching", IEEE Trans. Image Processing, vol. 9, no. 5, (2010), pp. 846-859.

[15] K. Kalle and A. K. Jain, "Fingerprint Classification", Pattern Recognition, vol. 8, no. 3, (1996), pp. 389-404.

[16] M. A. Bazen and S. H. Gerez, "Extraction of Singular Points from Directional Fields of Fingerprints", Mobile Communications in Perspective, Annual CTIT Workshop, Enschede, The Netherlands, University of Twente, Center for Telematics and Information Technology, (2001).

[17] M. Kawagoe and A. Tojo, "Fingerprint Pattern Classification", Pattern Recognition, vol. 17, no. 3, (1984), pp. 295-303.

[18] W. M. Koo and A. Kot, "Curvature-based singular points detection", Proceedings of 3rd International Conference on Audio- and Video-Based Biometric Person Authentication, Lecture Notes in Computer Science, Halmstad, vol. 2091, (2001), pp. 229-234.

[19] K. Nilsson and J. Bigun, "Complex Filters Applied to Fingerprint Images Detecting Prominent Symmetry Points Used for Alignment", Proceedings of ECCV Workshop on Biometric Authentification, (2002), pp. 3947.

[20] C. H. Park, S. K. Oh, D. M. Kwak, B. S. Kim, Y. C. Song and K. H. Park, "A New Reference Point Detection Algorithm Based on Orientation Pattern Labeling in Fingerprint Images", Proceedings of First Iberian Conf on Pattern Recognition and Image Analysis, Puerto de Andtratx, Spain, (2003).

[21] M. Liu, X. Jiang and A. C. Kot, "Nonlinear Fingerprint Orientation Smoothing by Median Filter", ICICS, (2005), pp. 1439-1443.

[22] X. Jiang, M. Liu and A. C. Kot, "Reference Point Detection for Fingerprint Recognition", Proceedings of the 17th IEEE International Conference on Pattern Recognition, (2004).

[23] K. J. Navrit and A. Kamra, “A Novel Method for Fingerprint Core Point Detection”, International Journal of Scientific \& Engineering Research, vol. 2, no. 4, (2011).

[24] Z. Weiwei and Y. Wang, "Singular Point Detection in Fingerprint Image", Proceedings of the 5th Asian Conference on Computer Vision, (2002) January 23-25, Melbourne, Australia.

[25] W. Liu, "Fingerprint Classification Using Singularities Detection", International Journal of Science and Research (IJSR), India, vol. 2, no. 1, (2013).

[26] A. Julasayvake and S. Choomchuay, “An Algorithm for Fingerprint Core Point Detection”, 1-4244-07796/07/\$20.00, IEEE, (2007), Available: http://citeseerx.ist.psu.edu/viewdoc/summary ?doi=10.1.1.106.6655, Accessed 12/02/2014.

[27] Q. Zhao, D. Zhang, L. Zhang and N. Luo, "Adaptive fingerprint pore modeling and extraction", Pattern Recognition, vol. 43, (2007), pp. 2833-2844.

[28] M. A. Usman, R. Arshad, R. Anwar and S. A. Khan, "Point Detection Using fine Orientation Field Estimation", International Conference on Computer Vision Theory and Applications, (2008).

[29] S. Young-Chul and S. J. Elliott, "Orientation and edge-map-based fingerprint core-point detection", Optical Engineering, vol. 47, no. 3, (2008).

[30] M. S. Khalil, D. Muhammad, M. K. Khan and K. Alghathbar, "Singular points detection using fingerprint orientation field reliability”, International Journal of Physical Sciences, vol. 5, no. 4, (2010), pp. 352-357. 
[31] S. Nakthanom, "Fingerprint Enhancement for Core Point Detection", Available: www.rmutsb.ac.th/actis2/actis2010/ACTIS2010-03.pdf. Accessed 23/02/2014.

[32] F. Su, P. Sun, B. Wang and A. Cai, "Fingerprint singular points extraction based on the properties of orientation model", The Journal of China Universities of Posts and Telecommunications, vol. 18, no. 1, (2011).

[33] Y. Mei, R. Hou and J. Wang, “An Improved Method for Fingerprints' Singular Points Detection based on Orientation Field Partition", International Journal of Signal Processing, Image Processing and Pattern Recognition, vol. 6, no. 1, (2013).

[34] H. B. Kekre and V. A. Bharadi, "Fingerprint Core Point Detection Algorithm Using Orientation Field Based Multiple Features", International Journal of Computer Applications, vol. 1, no. 15, (2013).

[35] W. Dawei, Y. Yin and D. Yang, "Singular Points Detection Based on Multi- Resolution in Fingerprint Images", Neuro-computing, vol. 74, (2011), pp. 3376-3388.

[36] R. D. Labati, A. Genovese, V. Piuri and F. Scotti, "Measurement of the Principal Singular Point in Contact and Contactless Fingerprint Images by using Computational Intelligence Techniques", (2010), Available: http://clem.dii.unisi.it/ vipp/files/prin/Measurement\%20of\%20the\%, 20Principal $\% 20$ Singular\%20Point $\% 20$ in $\% 20$ Contact $\% 20$ and $\% 20$ Contactless $\% 20$ Fingerprint $\% 20$ Images $\% 20$ by\%20using\%20Computational\%20Intelligence\%20Techniques.pdf, Accessed 13/04/2014.

[37] S. Basak, M. I. Islam and M. R. Amin, "Detection of Virtual Core Point of A Fingerprint: A New Approach", International Journal of Soft Computing and Engineering, vol. 2, (2012).

[38] S. Chang and S. Srihari, "Latent Fingerprint Core Point Prediction Based on Gaussian Processes", Proceedings of International Conference on Pattern Recognition, (2010) August 23-26, Istanbul, Turkey.

[39] K. S. Sim, Y. K. Tan, M. E. Nia and G. D. Lee, "Rotation-invariant Reference Point Location Detection Using Complex Filtering for Fingerprint Matching", International Journal of Future Computer and Communication, vol. 1, no. 3, (2012).

[40] M. R.Rahimi, E. Pakbaznia and S. Kasaei, "An Adaptive Approach to Singular Point Detection in Fingerprint Images”, International Journal of Electronics and Communications, vol. 58, no. 5, (2004), pp. 367-370.

[41] L. Chih-Jen, Y. Tai-Ning, J. I-Horng, C. Chun-Jung and L. Keng-Li, "Singular Points and Minutiae Detection in Fingerprint Images Using Principal Gabor Basis Functions", Available: http://citeseerx.ist.psu.edu/viewdoc/summary?doi=10.1.1.90.6590. Accessed 15/13/2013.

[42] D. Monro and B. Sherlock, "A Model for interpreting fingerprint topology", Pattern Recognition, vol. 26, no. 7, (1993), pp. 1047-1055.

[43] L. Hong, Y. Wau and A. Jain, "Fingerprint image enhancement: Algorithm and performance evaluation"; Pattern Recognition and Image Processing Laboratory, (2006), pp. 1-30.

[44] R. Cappelli, D. Maio, D. Maltoni, J. L. Wayman and A. K. Jain, "Performance Evaluation of Fingerprint Verification Systems", IEEE Transactions on Pattern Analysis and Machine Intelligence, vol. 28, no. 1, (2008), pp. 3-18. 
International Journal of Signal Processing, Image Processing and Pattern Recognition Vol.7, No.5 (2014) 